\title{
FAKTOR-FAKTOR PENENTU KEKRITISAN DAN PENGEMBANGAN KRITERIA INDIKATOR KEKRITISAN EKOSISTEM GAMBUT TROPIKA DI TRUMON DAN SINGKIL PROVINSI ACEH \\ (Determinant Factors of Criticality and Development Criteria Indicators for Critical Tropical Peat Ecosystem in Trumon and Singkil, Province of Aceh)
}

\author{
Aswandi $^{1,2^{*}}$, Ronggo Sadono ${ }^{3}$, Haryono Supriyo ${ }^{3}$ dan Hartono $^{4}$ \\ ${ }^{1}$ Program Doktor Ilmu Kehutanan, Fakultas Kehutanan Universitas Gadjah Mada, \\ Jl. Agro No. 1, Bulaksumur, Yogyakarta 55281. \\ ${ }^{2}$ Balai Penelitian Kehutanan Aek Nauli, Jl. Raya Parapat Km 10,5 Parapat 21174. \\ ${ }^{3}$ Fakultas Kehutanan Universitas Gadjah Mada, Jl. Agro No. 1, Bulaksumur, Yogyakarta 55281. \\ ${ }^{4}$ Fakultas Geografi Universitas Gadjah Mada, Jl. Kaliurang, Bulaksumur, Yogyakarta 55281.
}

*Penulis korespondensi. Tel: +628126209444; Email: andiasw@yahoo.com.

Diterima: 5 Desember 2014

Disetujui: 8 Juni 2015

\begin{abstract}
Abstrak
Hutan rawa gambut merupakan salah satu ekosistem spesifik dan kompleks. Terbatasnya pemahaman terhadap karakteristik biofisik dan sifat kritisnya menjadi akar masalah degradasi ekosistem gambut di Indonesia. Generalisasi penerapan kriteria lahan kritis menyebabkan penilaian menjadi tidak tepat, sehingga program rehabilitasi menjadi tidak efektif. Tujuan penelitian adalah menentukan faktor-faktor biofisik yang mempengaruhi tingkat kekritisan ekosistem gambut, dan mengembangkan kriteria dan klasifikasi tingkat kekritisan ekosistem gambut. Pengumpulan data dilaksanakan pada berbagai tipe penutupan hutan dan tingkat keterbukaan lahan gambut di Trumon dan Singkil, Provinsi Aceh. Analisis data meliputi analisis korelasi bivariat, analisis gerombol, dan analisis diskriminan. Karakteristik biofisik yang diukur adalah dinamika kedalaman muka air tanah, penurunan permukaan tanah, tingkat dekomposisi, unsur hara, kehilangan karbon, dan penutupan lahan. Hasil penelitian menunjukkan perubahan penutupan lahan dan pembangunan drainase mempengaruhi tingkat kekritisan ekosistem gambut. Perubahan tingkat dekomposisi gambut (nisbah $\mathrm{C} / \mathrm{N}$ ), perubahan kemasaman $(\mathrm{pH})$ dan dinamika kedalaman muka air tanah merupakan penciri penting tingkat kekritisan ekosistem gambut. Ketiga faktor penciri ini diharapkan menjadi masukan dalam penyempurnaan kriteria tingkat kekritisan lahan pada Permenhut No. P.32/Menhut-II/2009 terutama pada ekosistem gambut.
\end{abstract}

Kata kunci: degradasi lahan, ekosistem gambut, indikator kekritisan, kedalaman muka air tanah.

\begin{abstract}
Peat swamp forest is one specific and complex ecosystem. The limited understanding of the biophysical characteristics and critical properties are some root of problems peat ecosystem degradation in Indonesia. Generalizing in application of critical land criterions caused incorrect assessment, therefore the rehabilitation and management programs became ineffective. The objectives of the study was to determine the biophysical factors that influence the degree of criticality of peat ecosystem, and to develop criterion and classification of the criticality degree on peat ecosystem. Data collection was conducted on variety of forest cover types in Trumon and Singkil, Aceh Province. Data analysis included bivariate correlation analysis, analysis of clusters, and discriminant analysis. Biophysical characteristics were measured including the dynamics of the depth of the water table, rate of subsidence, level of decomposition, nutrient content, loss of carbon, and land/forest cover. Results showed land use change and drainage affects the critical level of peatland ecosystems. The change on level of peat decomposition (C/N ratio), soil acidity $(\mathrm{pH})$ and groundwater dynamics were the identifier of critical peatland ecosystems. In addition to the criteria in Regulation No. P.32 / Menhut-II/2009, the identifier factors were expected to be considered in the refinement of the criteria of the critical level of peat ecosystem.
\end{abstract}

Keywords: land degradation, peat ecosystem, critical indicators, water table depth.

\section{PENDAHULUAN}

Ekosistem gambut Indonesia memegang peran penting dalam pengaturan iklim global. Dari luas 40 juta hektar lahan gambut tropika, lebih kurang
20,6 juta ha berada di Indonesia (Wahyunto dkk, 2005). Ekosistem gambut memiliki fungsi strategis dalam pelestarian sumberdaya air, peredam banjir, pendukung berbagai keanekaragaman hayati, pengendali iklim dan sebagainya (Joosten, 2009; 
Hooijer dkk, 2010). Berbagai fungsi penting tersebut telah meningkatkan perhatian dunia terhadap kelestarian pengelolaannya. Tekanan konversi yang tinggi akibat peningkatan kebutuhan lahan, penebangan dan kebakaran mengakibatkan semakin luasnya lahan gambut terdegradasi (Hooijer dkk, 2010; Suwondo dkk, 2011). Berdasarkan inventarisasi, seluas 10,77 juta ha atau $51 \%$ dari luas lahan gambut Indonesia telah mengalami deforestasi dan seluas 2 juta ha rusak pada periode tahun 2000-2009 (Anonim, 2010).

Memperhatikan fungsi penting lahan gambut bagi sistem penyangga kehidupan, ekosistem ini harus dilindungi, dikelola secara bijaksana dan dikembalikan fungsinya apabila terdegradasi. Untuk mendukung keberhasilan pengelolaan dan rehabilitasinya diperlukan informasi yang tepat dan spesifik mengenai karakteristik biofisik dan sifat kritisnya (Krüger dkk, 2015). Keterbatasan pemahaman terhadap hal-hal tersebut merupakan salah satu akar masalah rendahnya kinerja rehabilitasi ekosistem gambut selama ini. Hal ini tercermin pada penilaian tingkat kekritisan hutan dan lahan yang digunakan saat ini. Kriteria dan indikator penilaian pada Permenhut No. P32/Menhut-II/2009 dinilai lebih mencerminkan karakteristik lahan kering, sehingga penerapannya pada lahan basah seperti ekosistem gambut memberikan hasil penilaian yang tidak sesuai.

Tujuan penelitian adalah menentukan faktorfaktor biofisik yang mempengaruhi tingkat kekritisan ekosistem gambut, dan mengembangkan kriteria dan klasifikasi tingkat kekritisan ekosistem gambut.

\section{METODE PENELITIAN}

\section{Waktu dan Lokasi}

Penelitian dilaksanakan selama empat belas bulan sejak Mei 2012 hingga November 2014. Pengumpulan data dilakukan pada berbagai tipe penutupan lahan gambut berupa hutan sekunder, areal terbuka/semak belukar, kebun campuran/ agroforest, perkebunan sawit dan lahan gambut primer di Trumon dan Singkil, Provinsi Aceh (Gambar 1).

\section{Prosedur Penelitian}

Penelitian dilakukan dengan mengukur tinggi muka air tanah, penurunan permukaan tanah (subsiden), ketebalan gambut, $\mathrm{pH}$, kandungan unsur hara dan intensitas penutupan vegetasi. Pengambilan data dilakukan dengan membangun dua jalur transek sepanjang $50 \mathrm{~m}$ pada masingmasing tipe penggunaan lahan dengan jarak antar jalur minimal $100 \mathrm{~m}$, tegak lurus terhadap saluran

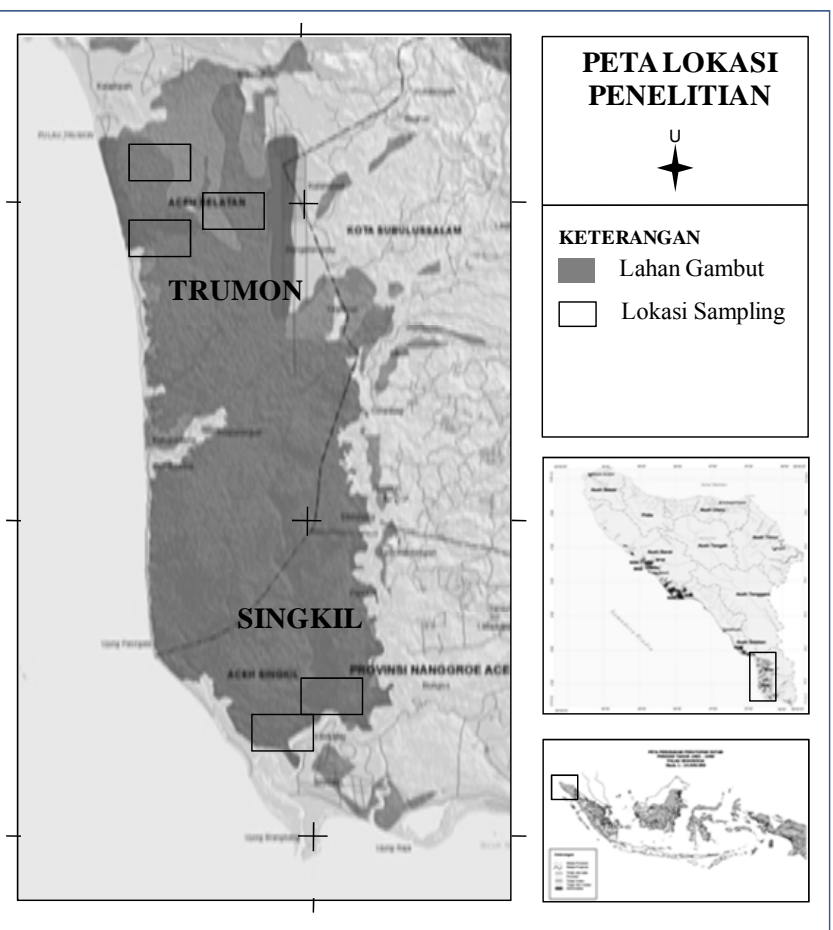

Gambar 1. Lokasi penelitian.

drainase. Pada pada interval jarak 3, 10, 25 dan 50 $\mathrm{m}$ dari tepi saluran diukur ketebalan gambut, kedalaman muka air, subsiden dan diambil sampel tanah. Pada lahan gambut primer, jalur transek dibuat tegak lurus terhadap garis kontur

Pengukuran kedalaman muka air dilakukan dengan memasang alat ukur berupa pipa berdiameter $6,35 \mathrm{~cm}$ dengan panjang $200 \mathrm{~cm}$ yang telah dilubangi. Kedalaman muka air diukur sebagai jarak muka air tanah terhadap permukaan tanah. Pengukuran dilakukan minimal setiap dua bulan terutama pada puncak kemarau dan musim hujan. Pengukuran ketebalan gambut dilakukan dengan menusukkan bor gambut hingga mencapai tanah mineral. Pada pengamatan subsiden, tongkat besi ditancapkan hingga tanah mineral dan batas permukaan tanah ditandai sebagai titik awal pengamatan. Pengamatan dilakukan setiap tiga bulan selama penelitian. Intensitas penutupan vegetasi dinilai berdasarkan kriteria yang terdapat pada Permenhut No. P32/Menhut-II/2009.

Pengambilan sampel tanah dilakukan menggunakan ring sample (tinggi $4 \mathrm{~cm}$ dan diameter 7,6 cm). Sampel tanah dianalisis di laboratorium untuk menentukan bobot isi dan kandungan unsur haranya. Kandungan C-organik diukur menggunakan Metode Walkley-Black, kandungan $\mathrm{N}$-total dihitung menggunakan metode Kjeldahl. Kation-kation dapat ditukar $\left(\mathrm{Ca}^{2+}, \mathrm{Mg}^{2+}\right.$, $\mathrm{K}^{+}$dan $\mathrm{Na}^{+}$ditetapkan dengan flamefotometer dan Atomic Absorption Spectrophotometer (AAS). Pengukuran KTK dilakukan dengan kolorimetri perkolat $\mathrm{NaCl}$. 
Analisis data meliputi analisis korelasi bivariat dan multivariat menggunakan perangkat lunak Minitab 14 for Windows, serta analisis tandan (cluster analysis), dan analisis diskriminan menggunakan perangkat lunak SPSS ver. 22.

\section{HASIL DAN PEMBAHASAN}

\section{Karakteristik Biofisik Lahan Gambut}

Hasil pengukuran menunjukkan terdapat keragaman kedalaman maksimum muka air, penurunan permukaan tanah (subsiden), $\mathrm{pH}$, bobot isi, tingkat kematangan, kandungan unsur hara (Corganik, $\mathrm{N}, \mathrm{Ca}, \mathrm{Mg}, \mathrm{K}$, KTK dan $\mathrm{KB}$ ), dan intensitas penutupan vegetasi pada berbagai tipe penggunaan dan keterbukaan lahan gambut di lokasi penelitian.

Gambar 2 menunjukkan keragaman maksimum kedalaman muka air tanah, laju subsiden, $\mathrm{pH}$, dan Nisbah $\mathrm{C} / \mathrm{N}$ pada berbagai tipe penggunaan lahan gambut. Rata-rata kedalaman muka air tanah maksimum tertinggi terukur pada tipe penggunaan lahan untuk perkebunan kelapa sawit dan semak belukar yang didrainase sedalam 53,35 dan 52,92 $\mathrm{cm}$. Pembangunan drainase ini mengakibatkan terjadinya subsiden akibat pemadatan, hilangnya karbon dan lepasnya air yang terikat pada tanah gambut (Maswar dkk., 2011;

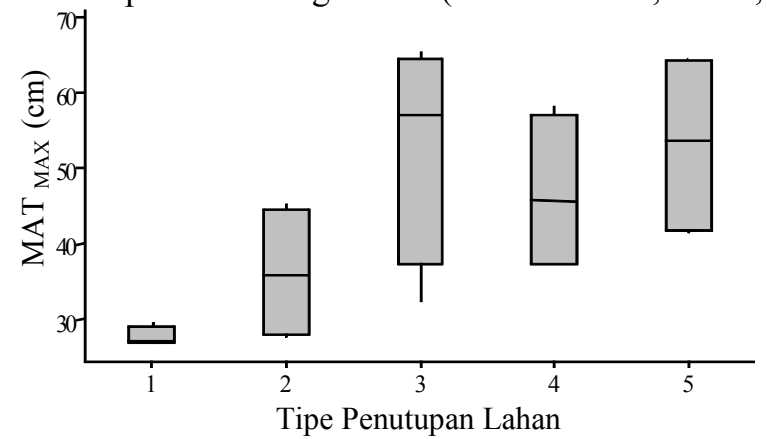

(a)

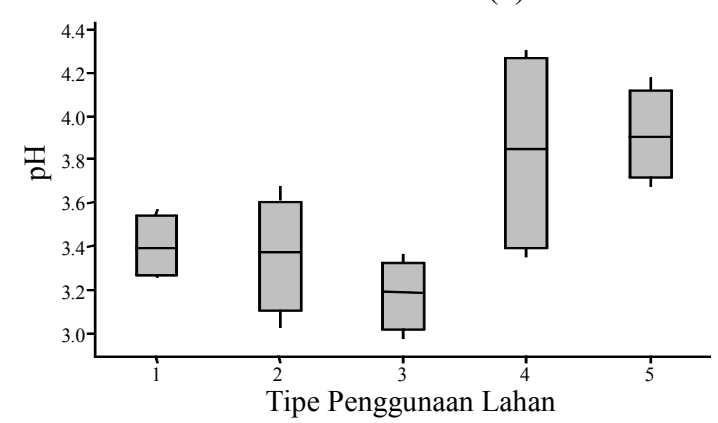

(c)
Nusantara dkk, 2014). Laju subsiden tertinggi terjadi pada lahan terbuka/ semak belukar sebesar $5,42 \mathrm{~cm} /$ tahun. Tidak adanya vegetasi dengan perakaran dalam pada lahan gambut yang hanya ditumbuhi semak belukar mengakibat subsiden berjalan lebih cepat (Dommain dkk, 2010).

Pembangunan drainase dan penebangan vegetasi selain menurunkan muka air dan menyebabkan subsiden, juga mempengaruhi tingkat kemasaman tanah (Maswar dkk, 2011; Lisnawati $\mathrm{dkk}, 2014)$. Pada lahan terbuka terjadi penurunan $\mathrm{pH}$ menjadi sangat masam $(\mathrm{pH}<3,17)$ dari $\mathrm{pH} 3,39$ pada kondisi primernya. Sebaliknya, terjadi peningkatan $\mathrm{pH}$ pada lahan perkebunan sawit dan kebun campuran/agroforest akibat pengapuran dan pemberian pupuk.

Keragaman tingkat kematangan pada berbagai tipe penggunaan lahan didukung oleh nilai bobot isi dan nisbah $\mathrm{C} / \mathrm{N}$ lahan gambut. Terdapat pengaruh yang cukup tinggi antara nisbah $\mathrm{C} / \mathrm{N}$ dengan tipe penggunaan lahan (Gambar 2.d). Lahan gambut dengan tingkat pengolahan yang intensif seperti perkebunan kelapa sawit dan kebun campuran/agroforest memiliki nisbah $\mathrm{C} / \mathrm{N}$ yang lebih rendah $(42,22$ dan 35,15) dibandingkan lahan yang tidak dikelola seperti lahan terbuka semak belukar, hutan sekunder dan hutan primer (nisbah $\mathrm{C} / \mathrm{N}=57,53-67,06)$.

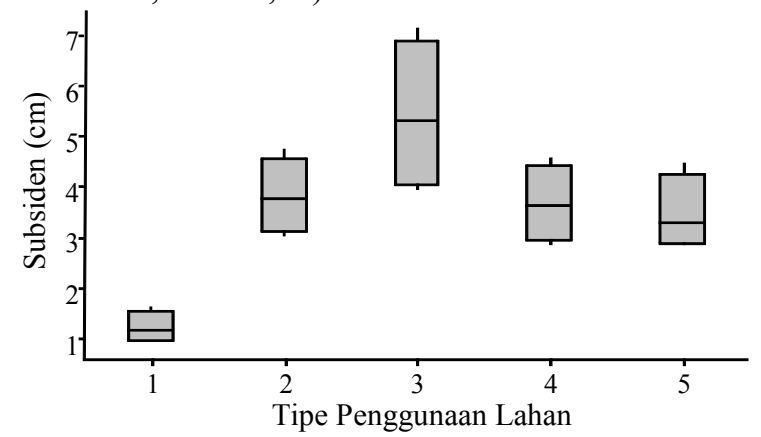

(b)

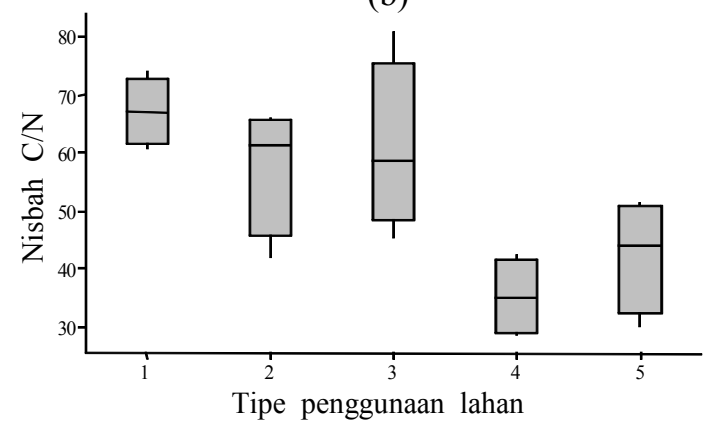

(d)

Gambar 2. Keragaman (a) kedalaman maksimum muka air tanah, (b) laju subsiden, (c) tingkat kemasaman tanah $(\mathrm{pH})(\mathrm{d})$ dan nisbah $\mathrm{C} / \mathrm{N}$ masing-masing pada berbagai tipe penggunaan lahan gambut. Keterangan tipe penggunaan lahan; 1 = hutan primer (ppf); 2 = hutan sekunder (spf); 3 = lahan terbuka/semak belukar (dpf); $4=$ kebun campuran/ agroforest (af); 5 = perkebunan kelapa sawit (pop). 


\section{Pengembangan Kriteria Kekritisan Lahan Gambut}

Kriteria tingkat kekritisan pada hutan dan lahan gambut dikembangkan berdasarkan faktorfaktor biofisik hutan dan lahan gambut seperti: ketebalan gambut, drainase dan dinamika kedalaman muka air, penurunan permukaan tanah (subsiden), bobot isi, kemasaman $(\mathrm{pH})$, , tingkat kematangan, C-organik, $\mathrm{N}$ total, nisbah $\mathrm{C} / \mathrm{N}, \mathrm{Ca}$, $\mathrm{Mg}, \mathrm{K}, \mathrm{KTK}$ dan KB serta intensitas penutupan vegetasi.

\section{Uji Korelasi}

Berdasarkan uji korelasi terhadap lima belas faktor biofisik hutan dan lahan gambut tersebut, terpilih delapan faktor yang memiliki korelasi signifikan terhadap tingkat kekritisan lahan yakni: kedalaman muka air tanah, laju subsiden, $\mathrm{pH}$, bobot isi, nisbah $\mathrm{C} / \mathrm{N}$, KTK dan $\mathrm{KB}$, dan intensitas penutupan vegetasi. Beberapa korelasi faktor biofisik yang dinilai dapat dilihat pada Gambar 3 dan Tabel 1.

\section{Klasifikasi Kelas Kekritisan}

Klasifikasi kelas kekritisan lahan gambut dilakukan menggunakan analisa gerombol (cluster analysis) dengan metode Average Linkage (Between Groups) dengan interval jarak Euclidean. Hasil analisis terhadap delapan faktor yang digunakan menunjukkan terdapat tiga kelas kelas

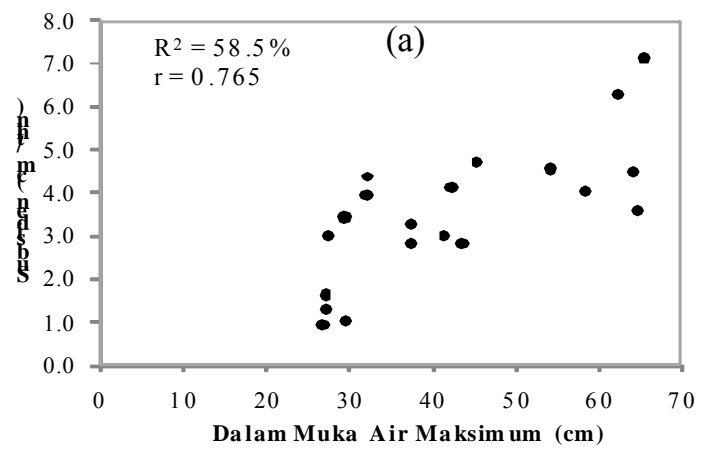

kekritisan ekosistem gambut yang optimal yaitu kelas Kritis (K), kelas Tidak Kritis dibangun Drainase (TKD) dan kelas Tidak Kritis Tidak Terganggu atau tidak ada pembangunan drainase (TKT). Dendrogram yang diperoleh dari analisis tandan dapat dilihat pada Gambar 4.

\section{Penyusunan Kriteria Kekritisan Hutan dan Lahan Gambut}

Penyusunan kriteria kekritisan lahan didasarkan pada asumsi bahwa setiap populasi diharapkan memiliki kovarian yang homogen (Sitorus dkk, 2011). Hasil uji Box's M terhadap faktor yang memenuhi homogenitas kovarian $(p>0,05)$ diperoleh lima faktor yakni: kedalaman muka air tanah, laju subsiden, $\mathrm{pH}$, nisbah $\mathrm{C} / \mathrm{N}$, dan intensitas penutupan vegetasi.

Faktor-faktor tersebut selanjutnya dianalisis diskriminan dengan metode stepwise. Metode stepwise mengeluarkan faktor-faktor yang terdeteksi saling kolinear (multikolinearitas), dengan sub metode mahalanobis distance untuk mengidentifikasi outlier (Sitorus dkk, 2011). Koefisien yang diperoleh pada fungsi linear digunakan untuk mengetahui faktor yang memberikan sumbangan terbesar terhadap terjadinya perbedaan antar kelas, sehingga koefisien tersebut dapat digunakan untuk melakukan pembobotan terhadap faktor yang terpilih (Priyanto, 2007; Sitorus dkk, 2011).

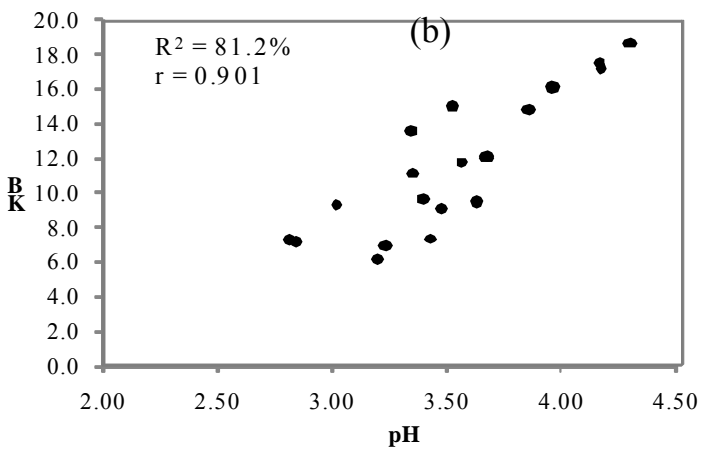

Gambar 3. Korelasi antar berbagai faktor biofisik lahan gambut. (a) Dalam muka air maksimum dengan subsiden dan (b) Kemasaman (pH) dengan Kejenuhan Basa (KB).

Tabel 1. Hasil analisis multivariat beberapa faktor biofisik lahan gambut.

\begin{tabular}{lccc}
\hline \multicolumn{1}{c}{ Persamaan } & $\mathrm{R}^{2}(\%)$ & $\mathrm{R}_{\text {adj }}^{2}(\%)$ & $\mathrm{S}$ \\
\hline$S=0,74+0,0818 M A T_{\max }-2,15 B D$ & 47,0 & 40,8 & 1,299 \\
$p H=4,65-0,00045 M A T_{\max }-0,19 B D-0,0200$ Nisbah $C / N$ & 60,1 & 52,6 & 0,264 \\
$p H=4,86-0,0628 S-0,0207$ Rasio $C / N$ & 67,5 & 63,7 & 0,231 \\
$p H=4,20+0,0137 M A T_{\max }-0,132 \mathrm{~S}-0,0146$ Rasio $C / N$ & 75,4 & 63,5 & 1,023 \\
$K T K=91,7+8,27 p H-0,144$ Nisbah $C / N$ & 37,0 & 29,5 & 6,989 \\
$K B=-8,16+6,77 p H-0,0783$ Nisbah $C / N$ & 84,9 & 83,1 & 1,608 \\
\hline
\end{tabular}

Sumber : Hasil analisis. Keterangan : $S=$ penurunan permukaan tanah (subsiden) $(\mathrm{cm} / \mathrm{tahun})$.

$M A T_{\max }=$ muka air tanah maksimal $(\mathrm{cm})$.

$B D=$ bobot isi (bulk density) $\left(\mathrm{g} / \mathrm{cm}^{3}\right)$. 


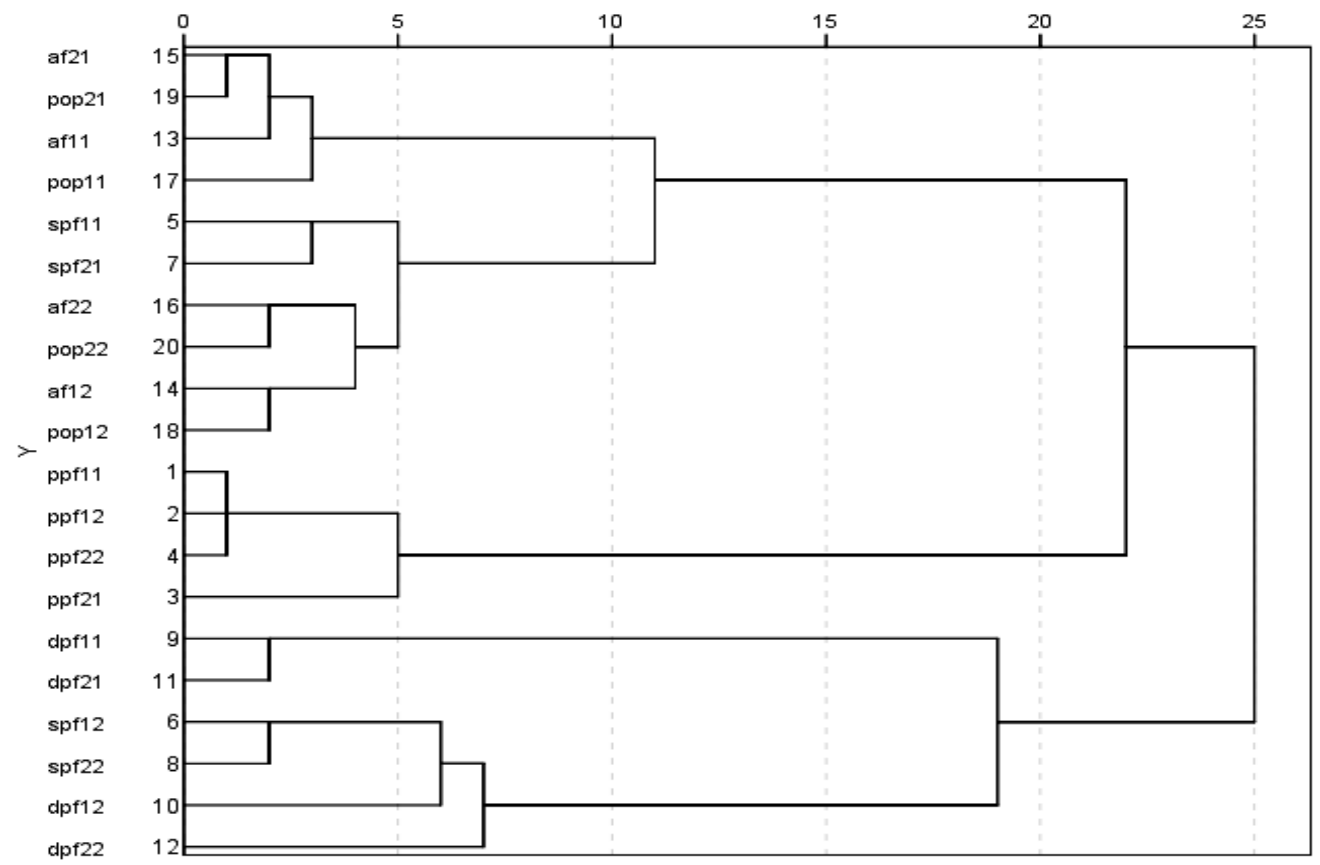

Gambar 4. Dendogram hasil analisis tandan (cluster analysis).

Dari hasil analisis multikolinearitas diperoleh tiga faktor yang terdeteksi tidak saling kolinear yakni: kedalaman maksimum muka air $\left(X_{1}\right) ; \mathrm{pH}$ $\left(X_{2}\right)$, dan nisbah $\mathrm{C} / \mathrm{N}\left(X_{3}\right)$. Dari analisis diskriminan diperoleh 2 fungsi linear yakni, fungsi $1(D=0,309$ $\left.X_{1}-0,591 X_{2}+0.851 X_{3}\right)$ dan fungsi $2(D=-0,598$ $\left.X_{1}+0,658 X_{2}+0,376 X_{3}\right)$. Berdasarkan uji signifikansi, fungsi diskriminan 1 (pertama) mempunyai kemampuan menjelaskan keragaman sebesar $82,3 \%$ dan sisanya dijelaskan oleh fungsi kedua. Fungsi 1 memiliki nilai eigenvalue yang tinggi yakni 2,429. Nilai eigenvalue yang tinggi $(>1)$ menunjukkan fungsi yang diperoleh sahih (Priyanto, 2007; Correa-Metrio, 2010). Berdasarkan uji Wilks' Lambda, fungsi 1 juga memiliki signifikansi yang tinggi $(p=0,00)$, dengan kemampuan menjelaskan keragaman hingga mencapai $100 \%$. Hal-hal ini menunjukkan bahwa fungsi yang terbentuk mampu mendiskriminasi yang baik.

Berdasarkan koefisien faktor-faktor yang memberikan sumbangan terbesar terhadap terjadinya perbedaan antar kelas dilakukan pembobotan masing-masing faktor yakni: kedalaman muka air tanah (18\%), kemasaman $(\mathrm{pH})$ (34\%), dan nisbah $\mathrm{C} / \mathrm{N}$ (48\%). Berdasarkan pembobotan tersebut, kekritisan lahan gambut dipengaruhi oleh faktor tingkat tingkat kematangan/ dekomposisi gambut dengan nilai pengaruh sebesar $34 \%$, sedangkan sisanya dipengaruhi kemasaman tanah sebesar $18 \%$ dan kedalaman muka air tanah dengan nilai pengaruh sebesar $18 \%$.
Ketiga faktor tersebut mendukung kriteria gambut terdegradasi yang dikemukakan Krüger dkk (2015) sekaligus menyesuaikan dengan karakteristik gambut tropika yang terdegradasi akibat akibat penebangan dan pembangunan drainase. Berdasarkan penelitian pada lahan gambut beriklim sedang di Jerman, diidentifikasi faktorfaktor kedalaman gambut, bobot isi, kemasaman dan dekomposisi (nisbah $\mathrm{C} / \mathrm{N}$ ) sebagai penciri kekritisan lahan gambut (Krüger dkk, 2015). Dalam hal ini, kedalaman gambut mengindikasikan dekomposisi aerob yang terjadi pada lapisan atas tanah gambut. Pada lahan gambut didrainase yang diteliti dalam penelitian ini, faktor kedalaman muka air lebih dominan mengindikasikan bagian gambut yang terdekomposisi secara aerob serta selanjutnya mempengaruhi karakteristik fisik dan kimia lahan gambut.

Berdasarkan nilai rata-rata dan titik potong dari masing-masing kelas kriteria tingkat kekritisan disusun selang nilai masing-masing faktor sebagaimana disajikan pada Tabel 2.

Berdasarkan selang nilai pada Tabel 2, suatu ekosistem gambut dinilai terdegradasi dan potensial menjadi lahan kritis apabila memiliki tingkat kematangan/dekomposisi yang sangat rendah (nisbah $\mathrm{C} / \mathrm{N}>60$ ), kemasaman tinggi $(\mathrm{pH}<3$ ) dan kedalaman maksimum muka air sangat dalam $(>60$ $\mathrm{cm})$. Suatu ekosistem gambut akan dinilai belum kritis apabila memiliki tingkat kematangan rendah (nisbah $\mathrm{C} / \mathrm{N}<40$ ), tingkat kemasaman tanah masam hingga sedang ( $\mathrm{pH} 4-5)$ dan dinamika muka air yang dangkal $(<30 \mathrm{~cm})$. 
Tabel 2. Selang nilai setiap kriteria dari faktor biofisik terhadap kekritisan ekosistem gambut.

\begin{tabular}{lccc}
\hline \multicolumn{1}{c}{ Faktor biofisik } & \multicolumn{3}{c}{ Selang nilai } \\
\cline { 2 - 4 } & Kriteria kritis & $\begin{array}{c}\text { Kriteria tidak kritis } \\
\text { drainase }\end{array}$ & $\begin{array}{c}\text { Kriteria tidak kritis } \\
\text { tidak terganggu }\end{array}$ \\
\hline $\begin{array}{l}\text { Kedalaman maksimum muka air } \\
\text { (Bobot 18\%) }\end{array}$ & $>60 \mathrm{~cm}$ & $40-60 \mathrm{~cm}$ & $<30 \mathrm{~cm}$ \\
Kemasaman tanah $(\mathrm{pH})$ & (sangat dalam) & $($ dalam $)$ & $($ dangkal) \\
(Bobot 18\%) & $\leq 3$ & $3-4$ & $4-5$ \\
Kematangan/ Dekomposisi (Nisbah C/N) & (sangat masam) & (sangat masam - masam) & $($ masam - sedang) \\
(Bobot 34\%) & $>60$ & $40-60$ & $<40$ \\
(sangat rendah) & (rendah-sedang) & (rendah) \\
\hline
\end{tabular}

Sumber : Hasil analisis. Keterangan : kriteria dan selang selai diperoleh dari rata-rata hasil penelitian.

Tabel 3. Kriteria dan indikator tingkat kekritisan hutan dan lahan gambut.

\begin{tabular}{|c|c|c|c|}
\hline Faktor biofisik (bobot \%) & Kriteria & Indikator & Skor \\
\hline Kedalaman maksimum muka air & 1. Sangat dalam & MAT $>60 \mathrm{~cm}$ & 3 \\
\hline \multirow{2}{*}{ (Bobot $18 \%)$} & Dalam & MAT $30-60 \mathrm{~cm}$ & 2 \\
\hline & Dangkal & MAT $<30 \mathrm{~cm}$ & 1 \\
\hline Kemasaman tanah $(\mathrm{pH})$ & Sangat masam & $\mathrm{pH}<3$ & 3 \\
\hline \multirow[t]{2}{*}{ (Bobot 34\%) } & Sangat masam - masam & pH 3-4 & 2 \\
\hline & Masam - sedang & $\mathrm{pH}>4$ & 1 \\
\hline Kematangan / dekomposisi (nisbah C/N) & 1. Dekomposisi sangat rendah & $\mathrm{C} / \mathrm{N}>60$ & 3 \\
\hline \multirow{2}{*}{ (Bobot $48 \%)$} & 2. Dekomposisi rendah & $\mathrm{C} / \mathrm{N} 40-60$ & 2 \\
\hline & 3. Dekomposisi sedang & $\mathrm{C} / \mathrm{N}<40$ & 1 \\
\hline
\end{tabular}

Sumber : Hasil analisis.

Tabel 4. Selang kelas kekritisan dan jumlah kumulatif skor tiap kelas.

\begin{tabular}{lc}
\hline \multicolumn{1}{c}{ Kelas kekritisan } & Jumlah skor \\
\hline Kritis & $\geq 201$ \\
Tidak kritis drainase & $<200$ \\
Tidak kritis tidak terganggu & $\leq 182$ \\
\hline
\end{tabular}

Sumber : Hasil analisis.

Selanjutnya berdasarkan hasil analisis dan seluruh uraian sebelumnya, diperoleh kriteria lahan kritis dan indikator seperti disajikan pada Tabel 3. Dengan menjumlahkan nilai (skor) dari indikator setiap faktor diperoleh selang nilai kekritisan beserta jumlah kumulatif setiap kelasnya sebagaimana disajikan pada Tabel 4.

Berdasarkan Tabel 4, suatu ekosistem hutan rawa gambut dinilai telah kritis apabila memiliki jumlah skor kumulatif $\geq 200$. Pada lahan gambut yang tidak didrainase, ambang batas kekritisan berada pada jumlah kumulatif 182. Pada lahan gambut yang telah dibangun drainase terutama untuk areal budidaya (perkebunan sawit dan kebun campuran) ambang batas kritis berada pada nilai 200.

Informasi sifat-sifat kritis ini meningkatkan pemahaman terhadap kondisi biofisik lahan gambut terdegradasi. Selain kriteria intensitas penutupan vegetasi yang telah diakomodasi dalam Permenhut No. P32/Menhut-II/2009, ketiga faktor penciri ini diharapkan dipertimbangkan dalam penyempurnaan kriteria tingkat kekritisan hutan dan lahan gambut.

\section{KESIMPULAN}

Perubahan penutupan lahan dan pembangunan drainase mempengaruhi kelestarian ekosistem gambut. Perubahan laju atau tingkat dekomposisi gambut (nisbah $\mathrm{C} / \mathrm{N}$ ), perubahan kemasaman tanah $(\mathrm{pH})$ dan dinamika kedalaman maksimum muka air tanah merupakan penciri kekritisan ekosistem gambut. Informasi sifat-sifat kritis ini meningkatkan pemahaman terhadap kondisi biofisik lahan gambut terdegradasi dan meningkatkan upaya rehabilitasi ekosistem hutan gambut.

\section{DAFTAR PUSTAKA}

Anonim, 2010. Keadaan Hutan Indonesia. Forest Watch Indonesia Global Forest Watch. Bogor.

Dommain, R., Couwenberg, J., dan Joosten, H. 2010. Hydrological Self-regulation of Domed Peatlands in South-east Asia and Consequences for Conservation and Restoration. Mires and Peat, 6(5):1-17.

Hooijer, A., Page, S., Canadell, J.G., Silvius, M., Kwadijk, J., Wösten, H., dan Jauhiainen, J., 2010. Current and Future $\mathrm{CO}_{2}$ Emissions from Drained Peatlands in Southeast Asia. Biogeosciences, 7:1-10.

Hommeltenberg, J., Schmid, H.P., Drösler, M., dan Werle, P. 2014. Can A Bog Drained for Forestry be A Stronger Carbon Sink than A Natural Bog Forest? Biogeosciences, 11:34773493. 
Correa-Metrio, A., Torres, K.R.C., dan Bush, M.B., 2010. Quantitifying Ecological Change through Discriminant Analysis: A Paleoecological Example from the Peruvian Amazon. Journal of Vegetation Science, 21(4):695-704.

Joosten, H., 2009. Peatland Status and Drainage Related Emissions in All Countries of the World. The Global Peatland $\mathrm{CO}_{2}$ Picture. Wetlands International. Wageningen.

Krüger, J.P., Leifeld, J., Glatzel, S., Szidat, S., dan Alewell, C., 2015. Biogeochemical Indicators of Peatland Degradation - A Case Study of A Temperate Bog in Northern Germany. Biogeosciences, 12:2861-2871.

Las, I. K., Nugroho, dan Hidayat, A., 2009. Strategi Pemanfaatan Lahan Gambut Untuk Pengembangan Pertanian Berkelanjutan. J. Pengembangan Inovasi Pertanian 2(4):295298.

Lisnawati, Y., Suprijo, H., Poedjirahajoe, E., dan Musyafa, M., 2014. Hubungan Kedekatan Ekologis Antara Fauna Tanah dengan Karakteristik Tanah Gambut yang Didrainase untuk HTI Acacia crassicarpa. Jurnal Manusia dan Lingkungan, 21(2):170-178.

Maswar, Haridjaja, O., Sabiham, O., dan van Noordwijk, M., 2011. Cadangan, Kehilangan, dan Akumulasi Karbon pada Perkebunan Kelapa Sawit di Lahan Gambut Tropika.
Journal of Soil and Land Utilization Management, 8(1):1-10.

Nusantara, R.W., Sudarmadji, S., Djohan, T.S., dan Haryono, E., 2014. Emisi $\mathrm{CO}_{2}$ Tanah Akibat Alih Fungsi Lahan Huta Rawa Gambut di Kalimantan Barat. Jurnal Manusia dan Lingkungan, 21(3):268-276.

Priyanto, 2007. Penerapan Analisa Diskriminan Dalam Pembedaan Kelas Umur Tegakan Pinus. J. Manajemen Hutan Tropika, 13(3):155-165.

Sitorus, S.R.P., Mashudi, dan Haridjaja, O., 2011. Pengembangan Kriteria dan Klasifikasi Lahan Kritis serta Keterkaitannya dengan Produktivitas Lahan di Kabupaten Bogor. Prosiding Seminar Nasional Sumberdaya Lahan Pertanian. Balai Besar Penelitian dan Pengembangan Sumberdaya Lahan Pertanian. Kementerian Pertanian. Bogor, 30 November 1 Desember 2010.

Suwondo, Sabiham, S., Sumardjo, dan Pramudya, B., 2011. Efek Pembukaan Lahan terhadap Karakteristik Biofisik Gambut pada Perkebunan Kelapa Sawit di Kabupaten Bengkalis. Jurnal Natur Indonesia, 14(2):143149.

Wahyunto, Ritung, S., dan Subagjo, H., 2005. Map of Peatland Distribution Area and Carbon Content in Sumatra. Wetland InternationalIndonesia Program and Wildlife Habitat Canada (WHC). Bogor. 